Dept. Vet. Medicine, Fac. of Agriculture and Vet. Medicine,

Qassim Univ., Saudi Arabia.

\title{
SCOMBROID FISH POISONING
}

Review

By

\author{
N.A. AL-WABEL \\ (Received at 3/9/2009)
}

\section{SUMMARY}

Scombroid fish poisoning, or scombrotoxin poisoning occurs when people eat scombroid or scombroid-like fish that have been carelessly handled and permitted to build up biogenic amines particularly histamine, as a consequence of bacterial spoilage. A level for histamine of $5 \mathrm{mg} / 100 \mathrm{~g}(50 \mathrm{ppm})$ is recommended for assuring the safe consumption of such fish, while a level of 1,500-4,000 $\mathrm{mg}$ histamine causes severe incidence. Symptoms such as headache, nausea, vomiting, diarrhoea, itching, oral burning sensation, red rash and hypotension are common in such cases. Rapid cooling of fish is of value to prevent formation of biogenic amines.

Key words: Fish, scombroid fish, scombrotoxin, biogenic amines.

\section{INTRODUCTION}

The presence of biogenic amines in foodstuffs is an important food safety problem because of the implication of these compounds in food intolerance and intoxication (Ferreira and Pinho, 2006). Biogenic amines are non-volatile amines formed by decarboxylation of amino acids. Although many biogenic amines have been found in fish, only histamine, cadaverine, and putrescine have been found to be significant in fish safety and quality determination (Al Bulushi et al., 2009). Scombroid poisoning is caused by the ingestion of foods (usually fish) that contain high levels of histamin and possibly other vasoactive amines and compounds. Histamine and other amines are formed by the growth of certain bacteria and the subsequent action of their decarboxylase enzymes on histidine and other amino acids in food, either during the production of a product such as Swiss cheese or by spoilage of foods such as fishery products, particularly tuna or mahi mahi. However, any food that contains the appropriate amino acids and is subjected to certain bacterial contamination and growth may lead to scombroid poisoning when ingested (FDA, 2001). 
Fish muscle is naturally rich in free amino acids and the content may increase even further post mortem. The high content of proteolytic enzymes in the intestinal tract is responsible for the rapid autolytic process and the high free amino acid content in fishery products (Aksnes, 1988). Scombroid poisoning, also called histamine or, scombrotoxin poisoning occurs when people eat fish that have been carelessly handled and permitted to build up biogenic amines such as histamine, cadaverine, and putrescine as a consequence of bacterial spoilage. Histamine has been identified as the causative agent of the disease Scombrotoxicosis, or scombroid poisoning, which can, in severe cases, cause symptoms such as headache, nausea, vomiting, diarrhoea, itching, oral burning sensation, red rash and hypotension. The disease was initially associated with the consumption of fish belonging to the Scombridae and Scomberosocidae species and hence the name Scombrotoxicosis (Rawles et al., 1996). The symptoms of histamine poisoning usually appear shortly after the food is ingested with a duration of up to $24 \mathrm{~h}$. Symptoms may be gastrointestinal (nausea, vomiting, diarrhea), circulatory (hypotension), cutaneous (rash, urticaria, edema, localized inflammation) and neurological (headache, palpitations, tingling, flushing or burning, itching). Antihistamines can be used effectively to treat the symptoms (Taylor et al., 1989).

\section{Causes of Scombrotoxin Poisoning:}

Despite a widely reported association between histamine and scombroid food poisoning, histamine alone appears to be insufficient to cause food toxicity. Putrescine and cadaverine have been suggested to potentiate histamine toxicity. With respect to spoilage on the other hand, only cadaverine has been found to be a useful index of the initial stage of fish decomposition. The relationship between biogenic amines, sensory evaluation, and trimethylamine during spoilage are influenced by bacterial composition and free amino acid content. A mesophilic bacterial count of $\log 6-7 \mathrm{cfu} / \mathrm{g}$ has been found to be associated with 5 $\mathrm{mg}$ histamine/100 $\mathrm{g}$ fish, the Food and Drug Administration (FDA) maximum allowable histamine level. (Al Bulushi et al., 2009). Biogenic amines, including histamine, can be formed in the fish anywhere during harvest, preparation and storage if conditions allow it. Biogenic amines may begin to develop after the fish dies on a hook or in a net, and will increase if the fish are left in the water too long after death or if they are not adequately chilled immediately after they are brought on board. In the case of histamine formation, such abuse allows a compound, called histidine, that is naturally occurring in all fish species, to be changed to 
histamine by bacteria present in the gills and gut. However, histidine that is readily available as free histidine is present in greater amounts in certain fish species thus increasing the likelihood that histamine will form quickly during improper handling and storage. Once histamine is formed it does not go away and no amount of washing or cooking will remove or destroy it. Likewise, freezing will not reduce or destroy histamine after it has formed. Prevention is the only way to assure that histamine is not in the fish in the first place (FDA, 2001). Biogenic amines represent a group of low-molecular-mass organic bases occurring in all organisms. In foods amines are usually generated by microbial decarboxylation of proteins, peptides and amino acids. They can have an aliphatic, aromatic or heterocyclic structure (Kř́žžek and Kalač, 1998).

The Food and Drug Administration established a guidance level for histamine of $5 \mathrm{mg} / 100 \mathrm{~g}$ (50 ppm) for assuring the safe consumption of scombroid or scombroid-like fish and recommended the use of other data to judge fish freshness, such as the presence of other biogenic amines associated with fish decomposition (FDA, 1996). A maximum average histamine content of $10 \mathrm{mg} / 100 \mathrm{~g}(100 \mathrm{ppm})$ has been established in the European Community (EC) for acceptance of tuna and other fish belonging to the Scombridae and Scomberesocidae families (Veciana-Nogues et al., 1997). The EC has suggested that in the future a maximum of $300 \mathrm{ppm}$ for total biogenic amines in fish and fish products may be an appropriate legal limit. It is important to note, however, that there may be a type of poisoning that does not arise from high levels of histamine. Thus a low histamine level may not be absolute assurance of a safe product. It may be more appropriate to say that the absence of decomposition in the fish renders it a safe product. As such, a safe product would have no evidence of spoilage including odors of decomposition, high histamine levels, and other amines such as cadaverine (FDA, 2001).

\section{Associated Foods:}

Fish products that have been implicated in scombroid poisoning include the tunas (e.g., skipjack and yellowfin), mahi mahi, bluefish, sardines, mackerel, amberjack, and abalone. Distribution of the toxin within an individual fish fillet or between cans in a case lot can be uneven, with some sections of a product causing illnesses and others not. Neither cooking, canning, or freezing reduces the toxic effect. Common sensory examination by the consumer cannot ensure the absence or presence of the toxin. Chemical testing is the only reliable test for evaluation of a product (FDA, 2001). It has been recognized for some 
time that biogenic amines occur in a wide range of foods, among them meat and meat products. The presence of these amines in food is of interest for two reasons: firstly, for toxicological reasons, in the sense that high levels of dietary biogenic amines can be toxic for certain consumers, and secondly, for their role as possible quality indicators (Ruiz-Capillas and Jimenez-Colmenero, 2004). The effect of the hygienic status of raw materials on biogenic amine production during ripening and storage (at 4 and 15 degrees $\mathrm{C}$ ) of fermented sausages was studied. Two portions of fresh lean and back fat pork were stored for 5 days at -20 degrees $\mathrm{C}$ (treatment $\mathrm{A}$ ) and at 4 degrees $\mathrm{C}$ (treatment $\mathrm{B}$ ), respectively. Raw materials of treatment $\mathrm{A}$ maintained their hygienic quality high and low amine content. Raw materials of treatment B showed from 1 to $3 \log (\mathrm{CFU} / \mathrm{g})$ higher microbial counts and a biogenic amine index near $50 \mathrm{mg} / \mathrm{kg}$, indicating poorer hygienic quality. The quality of raw materials influenced the composition and the concentration of biogenic amines produced during the ripening sausages (Bover-Cid, et al., 2000).

The following Figures represent the types of fish identified by FDA as being most likely to cause scombrotoxin poisoning (FDA, 2001):

Amberjack

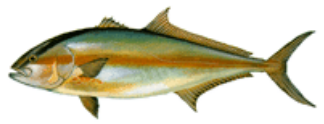

Bluefish

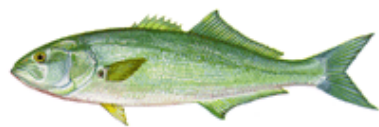

Bonito

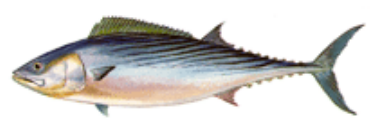

Herring

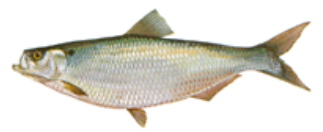

Jacks

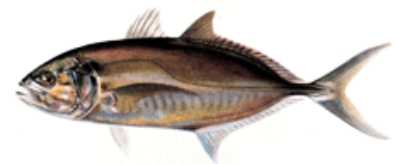

Mackerels

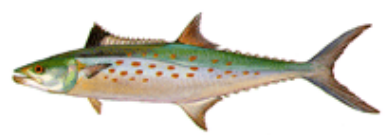

Mahi mahi (dolphin fish)

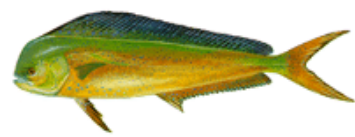

Marlin

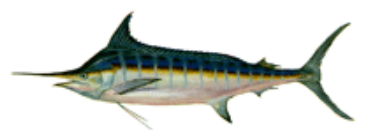

Shad

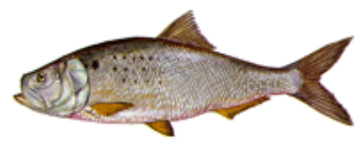

Sardines

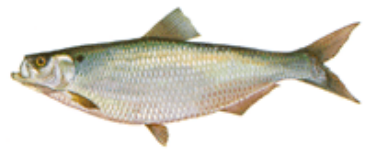

Tunas

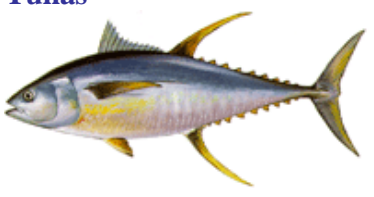

Wahoo

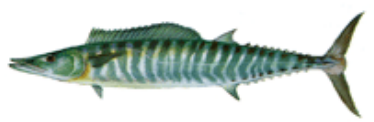




\section{Target Populations:}

All humans are susceptible to scombroid poisoning. The symptoms can be severe for the elderly and for those taking medications such as isoniazid. Because of the worldwide network for harvesting, processing, and distributing fishery products, the impact of the problem is not limited to specific geographical areas or consumption pattern. These foods are sold for use in homes, schools, hospitals, and restaurants as fresh, frozen, or processed products (FDA, 2001).

\section{Histamine Toxicity:}

Biogenic amines are low molecular weight organic bases that can be detected in raw and processed foods. Several toxicological problems resulting from the ingestion of food containing biogenic amines have been described. Biogenic amines are mainly produced by the decarboxylation of certain amino acids by microbial action. Since the ability of microorganisms to decarboxylate amino acid is highly variable, being in most cases strain-specific, the detection of bacteria possessing amino acid decarboxylase activity is important to estimate the risk of biogenic amine food content and to prevent biogenic amine accumulation in food products (Landete et al., 2007).

Histidine<smiles>N[C@@H](Cc1c[nH]cn1)C(=O)O</smiles>

$\mathrm{C} 00135$
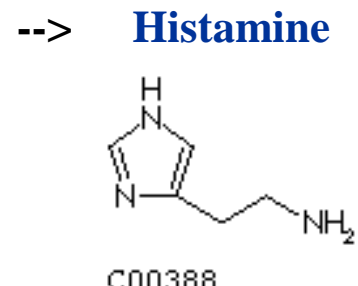

C00388

Douglas (1970) reported that very large amounts of histamine could be given orally without causing adverse effects. He attributed this to the conversion of histamine to inactive $\mathrm{N}$-acetylhistamine by intestinal microflora. However, Granerus (1968) showed that Human subjects given up to $67.5 \mathrm{mg}$ histamine orally did not produce any subjective or objective symptoms of histamine poisoning (Symptoms appeared also with tuna sandwiches containing 100, 150, and $180 \mathrm{mg}$ doses of histamine.

Generally, high histamine levels are able to cause a toxic response, but subsequent research has indicated that other factors may also be responsible. When Clifford et al. (1989) fed portions of spoiled mackerel containing $300 \mathrm{mg}$ histamine and mackerel associated with an 
incident diagnosed as scombrotoxicosis to volunteers, there were no significant observable effects. A second study by Clifford et al. (1991) was conducted on mackerel fillets associated with an outbreak of scombrotoxicosis. Statistical analysis failed to detect any differences in amine content between fillets shown to be scombrotoxic and those failing to induce nausea, vomiting, or diarrhea, and also failed to establish any significant relationships between the amine doses. It was concluded that no relationship exists between the concentrations of six amines (including histamine, cadaverine, and putrescine) and the onset of scombrotoxic symptoms. Moreover, Ienistea (1973) reported the deleterious effects in relation to the amount of histamine ingested at one meal as follows:

\begin{tabular}{|l||l|}
\hline Mild poisoning & $8-40 \mathrm{mg}$ histamine \\
\hline \hline $\begin{array}{l}\text { Disorders of moderate } \\
\text { intensity }\end{array}$ & $70-1,000 \mathrm{mg}$ histamine \\
\hline \hline Severe incidents & $\begin{array}{l}1,500-4,000 \mathrm{mg} \\
\text { histamine }\end{array}$ \\
\hline
\end{tabular}

Scombroid fish poisoning is an acute illness that occurs after eating fish containing high levels of histamine or other biogenic amines. Symptoms typically include facial flushing, sweating, rash, a burning or peppery taste in the mouth, diarrhea, and abdominal cramps and usually resolve within several hours without medical intervention. More severe symptoms (e.g., respiratory distress, swelling of the tongue and throat, and blurred vision) can occur and require medical treatment with antihistamines (MMWR, 2007).

\section{Toxicity Potentiators:}

Histamine appears not to be the sole factor in causing toxicity since cases have also been observed from low contents of histamine (Soares and Gloria 1994). Strong evidence exists that biogenic amines such as putrescine, cadaverine, spermine, and spermidine in fish tissue can potentiate the toxic effect of histamine by inhibiting intestinal histamine-metabolizing enzymes such as diamine oxidase (Hungerford and Arefyev 1992), potentiating histamine uptake, and liberating endogenous histamine in intestinal fluids (Halasz et al., 1994). It has been reported that fish implicated in a scombroid poisoning incident had high levels of inhibitors that interfere with histamine metabolism. 
Monoamineoxidase inhibitor drugs used for the treatment of depression, hypertension, and tuberculosis have also been observed to potentiate the toxic effect of histamine (Taylor, 1986).

Klausen and Lund (1986) reported that at $10{ }^{\circ} \mathrm{C}$ the high cadaverine contents of mackerel in comparison with herring could be responsible for mackerel often being implicated in scombroid poisoning and not herring, since histamine levels were similar in both. Cadaverine and putrescine, as well as other diamines, have been suggested to facilitate the transport of histamine through the intestinal wall and to increase its toxicity Fernandez-Salguero and Mackie (1987).

\section{Food Analysis:}

An official method was developed at FDA to determine histamine, using a simple alcoholic extraction and quantitation by fluorescence spectroscopy. There are other untested procedures in the literature (FDA, 2001) Biogenic amines, such as putrescine, cadaverine, and histamine, in fish can be indicators of spoilage and/or safety. Methanol extraction used for AOAC Official Methods 996.07 and 977.13 has resulted in low amine recoveries in fish. Extraction methodology was evaluated to improve recovery from fish tissue. Samples were evaluated for recovery of known quantities of biogenic amines added to tissue prior to extraction. Addition of $25 \% 0.4 \mathrm{~N} \mathrm{HCI}$ to the 75\% methanol-water extraction solvent (according to AOAC Official Methods 996.07 and 977.13) resulted in higher recoveries $(\mathrm{P}<0.05)$ of the biogenic amines. Putrescine recovery increased from $44+/-2$ to 100 $+/-14 \%$ in flounder and scup, and from $53+/-21$ to $119+/-27 \%$ in mackerel and butterfish; cadaverine recovery increased from $47+/-4$ to $106+/-15 \%$ (flounder/scup) and $58+/-24$ to $113+/-9 \%$ (mackerel/butterfish); histamine recovery increased from $54+/-13$ to 89 $+/-28 \%$ (mackerel). $\mathrm{MeOH}$ extraction resulted in comparable recovery from canned tuna, indicating that protein denaturation from processing may eliminate possible matrix interference. Acidification of the solvent resulted in a more complete extraction of the added amines to fresh/frozen fish tissue. This finding could indicate that current extraction procedures may cause biogenic amines to be underestimated (Richard et al., 2008). The separation and quantification of biogenic amines in foods is normally performed by chromatographic techniques using different analytical methods based on high-pressure liquid chromatography (UV or diode array and/or fluorometric detectors) and gas chromatography (with a mass spectrometry detector) (Ferreira and Pinho, 2006). 
Molecular methods for the early and rapid detection of these producer bacteria are becoming an alternative to traditional culture methods. PCR methods offer the advantages of speed, sensitivity, simplicity and specific detection of amino acid decarboxylase genes. Moreover, these molecular methods detect potential biogenic amine risk formation in food before the amine is produced (Landete et al., 2007).

\section{Prevalence of Biogenic Amines in Fish:}

The prevalence of biogenic amines in fish depends on several factors such as muscle type. Takagi et al. (1969) examined the amounts of histidine and histamine in 21 aquatic species during spoilage. Their conclusions were consistent with those of other researchers in that more histamine was produced in the red muscle fish such as tuna and mackerel than in white muscle species such as rockfish. Within a given fish species, more histidine and histamine were found in white than in red muscle.

\section{Diagnosis of Human Illness:}

Diagnosis of the illness is usually based on the patient's symptoms, time of onset, and the effect of treatment with antihistamine medication. The suspected food must be analyzed within a few hours for elevated levels of histamine to confirm a diagnosis (FDA, 2001).

\section{Selected Outbreaks:}

Between December 31, 1985, and January 4, 1986, three restaurants in Alabama and Tennessee received complaints of illness from nine customers and one employee who ate Pacific amberjack fish (also called yellowtail or kahala). One restaurant cook, who did not eat the fish, reported a transient red rash on the hands shortly after handling the fish. Ill persons reported no other menu items in common. The fish meals were prepared by grilling or frying. Three people sought medical evaluation. One had diastolic hypotension, and one had bronchospasm. All three were diagnosed as having food or fish allergy and were treated with an antihistamine. The symptoms of scombroid fish poisoning resemble those of a histamine reaction. Scombroid poisoning is a response to toxic by-products--not an allergic reaction to fish. Several large outbreaks of scombroid poisoning have been reported. In 1970, some 40 children in a school lunch program became ill from imported canned tuna. In 1973, more than 200 consumers across the United States were affected by domestic canned tuna. In 1979-1980 more than 200 individuals became ill after consuming imported frozen mahi mahi. Symptoms varied with each incident. In the 1973 situation, of the interviewed patients, $86 \%$ experienced nausea, 55\% diarrhea, 44\% 
headaches and $32 \%$ rashes. Other incidents of intoxication have resulted from the consumption of canned abalone-like products, canned anchovies, and fresh and frozen amberjack, bluefish sole, and scallops. In particular, shipments of unfrozen fish packed in refrigerated containers have posed a significant problem because of inadequate temperature control (MMWR 1986).

In July 1987, state and local public health officials in New Mexico investigated two cases of scombroid fish poisoning (histamine poisoning) in persons living in Albuquerque. A husband and wife had become ill within 45 minutes after eating dinner. Their symptoms included nausea, vomiting, diarrhea, headache, fever, flushing, and rapid pulse rate. An investigation by the Albuquerque Environmental Health Department found that the couple had shared a meal of grilled mahi mahi, pasta, salad, water, and wine. Their dog had eaten some of the fish and had vomited. Both of the patients had been treated with Benadryl, activated charcoal, and ipecac in a hospital emergency room. Their symptoms resolved within 36 hours of onset of illness (MMWR 1988).

Scombroid fish poisoning accounts for less than $0.5 \%$ of foodborne illnesses reported in the United States. During 1998-2002, a total of 118 scombroid fish poisoning outbreaks involving 463 persons were reported to CDC from state health departments (MMWR. 2006).

Prevention of Biogenic Amines Formation:

Biogenic amine concentrations ranged widely within individual food items, and storage, transport, and handling conditions can influence to some extent the biogenic amines present and their concentrations (Ferreira and Pinho, 2006). Fish should be rapidly retrieved from the water, and packed in ice, ice slush, chilled seawater, refrigerated seawater or chilled brine as quickly as possible using good handling procedures. Formation of biogenic amines is drastically reduced by cooling fish to $40^{\circ} \mathrm{F}$ (internal) as quickly as possible. It is known that larger fish take longer to cool then smaller fish. Evisceration (removal of the guts) of larger fish is a good way to remove the bacteria that cause formation of biogenic amines and ensuring that the gut cavity is packed with ice or is filled with cooling media allows quicker chilling of that critical part of the fish. Evisceration must be done carefully so that the guts do not contaminate the meat or other fish. Even if a fish smells good, histamine could still be present and cause illness if the fish has not been chilled rapidly and kept cold enough. Incidentally, proper chilling of the fish will prevent other spoilage bacteria from multiplying and will 
help ensure that you continue to provide the highest quality of fish available (FDA, 2001).

Therefore, the most effective prevention for scombroid fish poisoning is proper refrigeration of fish at $4.4^{\circ} \mathrm{C}$ at all times between catching and consumption. Sensory examination (i.e., by smell and taste) is not sufficient to detect the absence or presence of histamine; chemical testing is required (MMWR. 2007).

\section{REFERENCES}

Aksnes, A. (1988): Location of enzymes responsible for autolysis in bulk-stored capelin (Mallotus villosus). J. Sci. Food Agric. 44: 263-71.

Al Bulushi, I.; Poole, S.; Deeth, HC. and Dykes, GA. (2009): Biogenic amines in fish: roles in intoxication, spoilage, and nitrosamine formation--a review. Crit. Rev. Food Sci. Nutr. 49(4): 369-77.

Bover-Cid, S.; Izquierdo-Pulido, M. and Vidal-Carou, MC. (2000):

Influence of hygienic quality of raw materials on biogenic amine production during ripening and storage of dry fermented sausages. J. Food Prot. 63(11): 1544-50.

Clifford, M.N.; Walker, R.; Ijomah, P.; Wright, J.; Murray, C.K. and Hardy, R. (1991): Is there a role for amines other than histamines in the aetiology of scombrotoxicosis. Food Addit. Contam. 8(5): 641-52.

Clifford, M.N.; Walker, R.; Wright, J.; Hardy, R. and Murray, C.K. (1989): Studies with volunteers on the role of histamine in suspected scombrotoxicosis. J. Sci. Food Agric. 47: 365-75.

Douglas, W.W. (1970): Histamine and antihistamines; 5Hydroxytryptamine and antagonists. In: Goodman LS, Gilman A, editors. The pharmacological basis of therapeutics. $5^{\text {th }}$ ed. New York: Macmillan. p 621-62.

FDA "Food and Drug Administration" (2001): U.S. Food and Drug Administration Center for Food Safety and Applied Nutrition March 29: 2001.

FDA "Food and Drug Administration" (1996): Fish and fisheries products hazards and controls guide: $1^{\text {st }}$ edition. Washington D.C.: FDA, Center for Food Safety and Applied Nutrition, Office of Seafood. 
Fernandez-Salguero, J. and Mackie, I.M. (1987): Technical note: Preliminary survey of the content of histamine and other higher amines in some samples of Spanish canned fish. Int. J. Food Sci. Tech. 22: 409-12.

Ferreira, I.M. and Pinho, O. (2006): Biogenic amines in Portuguese traditional foods and wines. J Food Prot. 69(9): 2293-303.

Granerus, G. (1968): Effects of oral histamine, histidine, and diet on urinary excretion of histamine, methylhistamine, and 1-methyl4-imidazoleacetic acid in man. Scand J. Clin. Lab. Invest. Suppl. 10(4): 49-58.

Halasz, A.; Barath, A.; Simon-Sarkadi, L. and Holzapfel, W. (1994): Biogenic amines and their production by microorganisms in food. Trends Food Sci Technol 5:42-9. Hardy R, Smith JGM. 1976. The storage of mackerel (Scomber scombrus). Development of histamine and rancidity. J. Sci. Food Agric. 27: 595-9.

Hungerford, J.M. and Arefyev, A.A. (1992): Flow-injection assay of enzyme inhibition in fish using immobilized diamine oxidase. Analytica Chimica Acta 261: 351-9.

Ienistea, C. (1973): Significance and detection of histamine in food. In: Hobbs BC, Christian JHB, editors. The microbiological safety of foods. New York: Academic Press. p 327-43.

Klausen, N.K. and Lund, E. (1986): Formation of biogenic amines in herring and mackerel. Z Lebensm Unters Forsch 182(6):459-63.

Krrižek, M. and Kalač, P. (1998): Biogenic amines in foods and their role in nutrition. Czech J.Food Sci., 16, č.4, s. 151-159.

Landete, JM.; De Las Rivas, B.; Marcobal, A. and Muñoz, R. (2007): Molecular methods for the detection of biogenic amineproducing bacteria on foods. Int. J. Food Microbiol. 15; 117(3): 258-69.

MMWR "Morbidity and Mortality Weekly Reports" (1986): Epidemiologic notes and reports: restaurant-associated scombroid fish poisoning-Alabama, Tennessee, 35(16): 264-265.

MMWR "Morbidity and Mortality Weekly Reports" (1988): Scombroid fish poisoning-New Mexico, 1987. 37(29):451.

MMWR "Morbidity and Mortality Weekly Reports" (2006): Surveillance for foodborne-disease outbreaks-United States, 1998-2002. 
MMWR "Morbidity and Mortality Weekly Reports" (2007): Scombroid fish poisoning associated with tuna steaks-louisiana and Tennessee, 2006. 56:817-819.

Rawles, D.D.; Flick, G.J. and Martin, R.Y. (1996): Biogenic amines in fish and shellfish, in Advances in Food and Nutrition Research, Vol. 39, p. 329-365.

Richard, N.; Pivarnik, L.; Ellis, PC. and Lee, C. (2008): Effect of matrix on recovery of biogenic amines in fish. J AOAC Int. 91(4): 768-76.

Ruiz-Capillas, C. and Jiménez-Colmenero, F. (2004): Biogenic amines in meat and meat products. Crit. Rev. Food Sci. Nutr. 44: 7-8.

Soares, V.F.M. and Gloria, M.B.A. (1994): Histamine levels in canned fish available in the retail market of Belo Horizonte, Minas Gerais, Brazil. J. Food Comp. Anal. 7: 102-9.

Takagi, M.; Iida, A.; Murayama, H. and Soma, S. (1969): On the formation of histamine during loss of freshness and putrefaction of various marine products. Bull. Fac. Fish, Hokkaido Univ. 20: 227-34.

Taylor, S.L. (1986): Histamine food poisoning: toxicology and clinical aspects. CRC. Crit. Rev. Toxicol. 17(2): 91-128.

Taylor, S.L.; Stratton, J.E. and Nordlee, J.A. (1989): Histamine poisoning (scombroid fish poisoning): an allergy-like intoxication. Clin. Toxicol. 27(4\&5): 225-40.

Veciana-Nogues, M.T.; Marine-Font, A. and Vidal-Carou, M.C. (1997): Biogenic amines as hygienic quality indicators of tuna. Relationships with microbial counts, ATP-related compounds, volatile amines and organoleptic changes. J. Agric. Food Chem. 45: 2036-41. 